\title{
Жизнь и эволюция идейно-политических воззрений Генри Макнила Тернера
}

\author{
Шумаков А.А. \\ Тульский филиал Российского экономического университета им. Г.В. Плеханова, \\ Россия, 300000, г. Тула, проспект Ленина, 53 \\ E-mail: takamori@rambler.ru
}

\begin{abstract}
Аннотация. Данная статья является первой в отечественной академической науке попыткой изложения биографии и критического анализа религиозно-политической философии одного из первых и самых известных идеологов черного национализма в США - епископа Африканской методистской епископальной церкви (AME) Генри МакНила Тернера. В данной работе автор рассматривает динамику и причины трансформации его идейно-политических воззрений на протяжении всего периода жизни (1834-1915), предлагая собственную периодизацию. В заключении, помимо всего прочего, делается вывод о причинах современной популярности идеологии черного национализма и лично Генри Тернера в США, которые связываются с циклами развития социально-политической системы. Некоторые источники впервые введены в научный оборот.
\end{abstract}

Ключевые слова: Генри МакНил Тернер, черный национализм, интеграционизм, Движение за права чернокожих в США, Африканская методистская епископальная церковь (AME), аболиционизм, панафриканизм, репатриация.

Для цитирования: Шумаков А.А. 2021. Жизнь и эволюция идейно-политических воззрений Генри Макнила Тернера. Via in tempore. История. Политология, 48 (2): 349-358. DOI: $10.52575 / 2687-0967-2021-48-2-349-358$.

\section{The life and evolution of the ideological and political views of Henry Macneal Turner}

\author{
Andrey A. Shumakov \\ Plekhanov Russian University of Economics in Tula, \\ 53 Lenin Avenue, Tula, 300000, Russia \\ E-mail: takamori@rambler.ru
}

\begin{abstract}
This article is the first attempt in Russian academic science to present the biography and critical analysis of the religious and political philosophy of one of the first and most famous ideologists of black nationalism in the United States - bishop of the African Methodist Episcopal Church (AME) Henry McNeal Turner. In this paper, the author examines the dynamics and reasons for the transformation of his ideological and political views throughout the entire period of his life (1834-1915), offering his own periodization. In the conclusion of this article, among other things, the author concludes about the reasons for the current popularity of the ideology of black nationalism and Henry Turner personally in the United States, which are associated with the cycles of development of the socio-political system. Turner was a renowned priest, eminent orator and publicist. Interest in his person and theoretical heritage among researchers in the West began to wake up relatively recently - in the mid-1970s.
\end{abstract}

Key words: Henry McNeal Turner, black nationalism, integrationism, The black rights movement in the United States, The African Methodist Episcopal Church (AME), abolitionism, pan-africanism, repatriation.

For citation: Shumakov A.A. 2021. The life and evolution of the ideological and political views of Henry Macneal Turner. Via in tempore. History and political science, 48 (2): 349-358 (in Russian). DOI: $10.52575 / 2687-0967-2021-48-2-349-358$. 


\section{Введение}

Этого человека называют одним из самых ярких и авторитетных представителей Движения за права чернокожего населения в США, а также одним из первых идеологов черного национализма. Стоит отметить, что именно его взгляды оказали огромное влияние на Маркуса Гарви, который позаимствовал у Генри Тернера не только его знаменитую концепцию «черного Иисуса Христа», но и саму идею теологического обоснования необходимости возвращения афроамериканского населения на Черный континент, за что был прозван черным Моисеем [Turner, 1897]. Как и легендарный «ямайский мессия», Тернер был известным священником, выдающимся оратором и публицистом. Его несомненные заслуги в деле борьбы за права чернокожего населения и пробуждения афроамериканского самосознания никогда не ставились под сомнение даже его самыми ярыми оппонентами, всегда отдававшими должное таланту, принципиальности и авторитету епископа Африканской методистской епископальной церкви (АМЕ).

Однако, несмотря на все это, фигура Генри МакНила Тернера всегда находилась как бы в тени других выдающихся представителей и теоретиков указанного Движения, таких как Фредерик Дуглас, Уильям Эдуард Беркхардт Дюбуа, Эдвард Блайден, Букер Вашингтон и прочих, творивших на рубеже XIX и XX ст.

\section{Результаты и их обсуждение}

Интерес к его персоне и теоретическому наследию у исследователей на Западе начал просыпаться относительно недавно - в середине 1970-х гг., когда, казалось бы, острота расовых противоречий в американском обществе начала понемногу спадать, а сама идея репатриации потеряла свою былую актуальность и привлекательность для большей части негритянского населения в США. Именно в это время начинают выходить академические работы, посвященные жизнеописанию и наследию знаменитого афроамериканского проповедника. Среди них, в частности, можно упомянуть магистерские диссертации Элберта Мартина [Martin, 1975], Тюссена Фостера [Foster, 1976], Стефена Энджелла [Angell, 1988], Лоуренса Литтла [Little, 1993], Андре Джонсона [Johnson, 2008], Аарона Треадвелла [Treadwell, 2017] и ряда других авторов, вновь поднявших вопрос о значении и роли личности Генри МакНила Тернера в истории США и афроамериканского народа.

К сожалению, отечественная академическая наука до настоящего момента совершенно игнорировала указанную фигуру. Достаточно отметить, что не вышло не только ни одного исследования, посвященного знаменитому афроамериканскому епископу, но и ни одной статьи, ни одна из его работ или речей не была переведена на русский язык. Имя Генри Тернера можно встретить разве что в виде отдельных упоминаний в ряде исследований, например, в кандидатской диссертации С.А. Армейскова [Армейсков, 2010], где оно приводится в числе видных афроамериканских лидеров конца XIX - начала XX вв. А между тем именно Тернер одним из первых сформулировал ключевые положения доктрины «черного национализма». Примечательно, что в отличие от своего предшественника Мартина Делани [Шумаков, 2020, с. 61] он не отказался от своих взглядов, отстаивая их до конца своих дней.

Основная же значимость данной работы заключается в том, что она является фактически первой попыткой критического исследования биографии и философии Генри Тернера. Без подробного анализа профессионально-личностного становления и трансформации идейно-политических воззрений данного деятеля невозможно проследить генезис доктрины «черного национализма» в США, а также понять причины ее живучести и очередного возрождения ее популярности в современном американском обществе.

Ранние годы (1834-1862). Генри МакНил Тернер родился 1 февраля 1834 г. в Ньюберри, Аббевилл, штат Южная Каролина, в семье свободного мулата Харди Тернера и негритянки Сары Грир. Согласно семейной легенде, дед по материнской линии являлся африканским принцем зулусского племени. Собственно, это и спасло его от рабства после 
пленения и прибытия в кандалах в Южную Каролину. Согласно королевскому закону тогда еще английской колониальной провинции, его порабощение было признано незаконным, и пленник был немедленно освобожден. Однако принц, получивший по прибытии имя Дэвида Грира, не захотел возвращаться на родину и вскоре женился на свободной женщине. У пары родилась дочь - Сара. Отец же Генри Тернера также был сыном чернокожего раба и белой женщины-плантатора, что по закону того же штата делало их детей свободными.

Воспитанием Генри Тернера занималась бабушка Ханна и мать. Это во многом предопределило его дальнейшую судьбу и обусловило выбор будущей профессии. Генри рос набожным подростком, мечтая о духовном сане. По словам самого Тернера, в восемь лет мальчику приснилось, что он стоит перед большой смешанной толпой, которая ждет его наставлений [Johnson, 2017]. Генри воспринял это сновидение как божественный знак и с той поры всецело посвятил себя изучению Библии и богословия. Впрочем, обучиться грамоте для молодого человека с «неправильным» цветом кожи представлялось существенной проблемой, т. к. по законам штата негритянских детей воспрещалось учить грамоте под страхом тюремного заключения. Однако мать на свой страх и риск все же попыталась дать начальное образование сыну, прибегая к услугам наемного учителя по воскресным дням [Ponton, p. 34]. Это, безусловно, наложило определенный отпечаток на формирование его идейно-политических воззрений. Тернер стал убежденным аболиционистом, буквально одержимым идеей просвещения.

В 14 лет он переехал в Аббевилл, где устроился на работу уборщиком в офис юридической фирмы, получив тем самым доступ к литературе и возможность присутствовать на судебных заседаниях [Ponton, p. 34]. В 1851 г. вся семья Тернеров получила членство в Южной методистской епископальной церкви (SMEC), а сам Генри проходил обучение под руководством миссионера с плантации Сэмуэля Лирда. Спустя два года мечта Тернера осуществилась - он был рукоположен в духовный сан странствующего проповедника, позволивший ему перемещаться по всему Югу и выступать как перед чернокожими, так и перед белыми прихожанами. Судя по всему, уже тогда проповеди юного пастора пользовались большой популярностью, т. к. в ходе этих турне удалось собрать довольно внушительную по меркам того времени сумму пожертвований - 810 долларов [Johnson, 2017].

В 1858 г., опасаясь похищения и продажи в рабство, молодой проповедник меняет место жительства и переезжает в Сент-Луис, штат Миссури. Принятие Закона о беглых рабах 1850 г., акта Канзас - Небраска 1854 г., а также вынесение решения по делу Дреда Скотта в 1857 г. повысили спрос на рабов, заставив многих свободных афроамериканцев переживать за свою дальнейшую судьбу. В это время Тернер уходит из SMEC и вступает в Африканскую методистскую епископальную церковь (AME), где был взят под опеку знаменитым епископом и сторонником просвещения Дэниелом Пейном, продолжая обучение. Вскоре молодой человек переезжает в Балтимор, где какое-то время работает в медицинском колледже, а затем в Вашингтон, округ Колумбия, где в 1862 г. становится пастором влиятельной Африканской методистской епископальной церкви Израиля. К тому моменту Тернер уже прошел курс изучения грамматики английского, иврита, латыни, греческого, немецкого языка, ораторского искусства и по меркам своего времени считался вполне образованным человеком. Его проповеди собирали немалое количество слушателей самого различного социального статуса и расовой принадлежности.

Начавшаяся в 1861 г. гражданская война заставила Тернера пересмотреть свои взгляды. В 1862 г. он организует лекторий, служивший площадкой для обмена мнениями. В то же время Тернер становится корреспондентом еженедельной газеты AME «Christian Recorder» и устанавливает связи с рядом республиканских чиновников, чему способствовали его регулярные посещения Капитолийского холма. Стоит отметить, что на тот момент вашингтонский пастор был достаточно скептично настроен по отношению к республиканской партии США и лично к Аврааму Линкольну. В частности, в марте 1862 г. Тернер пи- 
сал: «Но к какому выводу мы приходим в отношении истинного духа послания [президента Линкольна]! Очень многих здесь оно ослепило и заставило поверить, что это предвещает надежду на светлое будущее; но я смотрю на данное послание как на одну из самых хитроумных уловок, направленных на умиротворение гуманных и человеколюбивых сердец страны. И я верю, что это приведет Север к тому же, что и Народный суверенитет сенатора Дугласа сделал с Южной Каролиной» [Turner, 1862].

Однако постепенно позиция проповедника меняется. Уже в сентябре на страницах того же издания Тернер публикует высокопарный призыв, который завершается словами: «Но прокламация президента Линкольна рассеяла туман и заглушила все сомнения. Теперь все могут видеть, что твердое намерение президентской политики заключается в том, чтобы вести войну во имя свободы, пока последний стон страдающего сердца раба не будет заглушен в ушах истинного Бога. Это определение политики побуждает нас подняться и самим думать и действовать. Мы стояли неподвижно и видели спасение Божье, в то время как мы молили его со слезами на глазах и кровоточащими сердцами; но день неподвижности простился с нами 22 сентября 1862 года. Новая эра, новое устройство вещей, теперь на нас самих, к действию, к действию, это крик. Теперь мы должны начать думать, планировать и издавать законы для самих себя» [A Call to Action, 1862].

Республиканец и интеграционист (1862-1868). В 1863 г. Тернер, уже как убежденный сторонник республиканской партии, агитирует за активное вступление афроамериканцев в армию Союза наряду с другими известными представителями негритянского движения Мартином Робинсоном Делани и Фредериком Дугласом и участвует в формировании 1-го пехотного полка Цветных войск Соединенных штатов (USCT). После достижения квоты в 1 тыс. чел. 29-летний пастор подал прошение о назначении его капелланом собранного полка. В ноябре 1863 г. Авраам Линкольн лично удовлетворил это прошение, сделав Тернера первым чернокожим капелланом в армии Союза. Сразу приступить к исполнению обязанностей не удалось, т. к. вскоре он заболел оспой и в течение нескольких месяцев боролся с тяжелой болезнью.

24 мая 1864 г. рота, в составе которой служил Тернер, участвовала в битве у форта Покахонтас, а затем в боях под Петербургом и Ричмондом и в массированной атаке на форт Фишер. Весной 1865 г. чернокожий капеллан вместе со своим отрядом принял участие в знаменитом Марше Шермана. После затухания боевых действий Тернер получил назначение на острове Роанок, где какое-то время наблюдал за поселением чернокожих.

После демобилизации в сентябре 1865 г. Тернер продолжил служить капелланом, но уже в составе другого цветного полка в Джорджии, где был прикомандирован к местному Бюро вольноотпущенников, а спустя год был избран в палату представителей, приняв самое активное участие в создании республиканской партии в указанном штате. На тот момент он придерживался примирительной интеграционистской позиции. 1 января 1866 г. в одной из своих самых знаменитых речей, посвященных празднованию Дня освобождения, Тернер заявил: «Я с нетерпением жду того дня, когда белые люди Юга не проявят и половины того предубеждения, которое они проявляют сегодня на севере, потому что они знают нас, а мы знаем их. Но в настоящее время они раздражительны, потому что считают себя покоренными, в то время как самый бедный класс в лучшем случае никогда не любил нас» [Turner, 1866]. А закончил он и вовсе словами: «Давайте любить белых, и пусть прошлое останется в прошлом, не насмехаться и не оскорблять их за былые обиды, а уважать их, почитать их, работать на них, но все же будем при этом оставаться людьми. Давайте покажем им, что мы можем быть народом почтенным, добродетельным, честным и трудолюбивым, и вскоре их предрассудки растают, и с Богом для нашего отца мы все будем братьями» [Turner, 1866]. После войны чернокожий проповедник не только находил необходимым и взаимовыгодным сосуществование двух рас, но и оправдывал рабство божественным предопределением [Turner, 1866]. 
Переходный период: от интеграционизма к «черному национализму» (1868-1915). Однако в 1868 г. взвешенный оптимизм Тернера в отношении американского будущего своей расы резко сменяется пессимизмом. Причиной стало постановление законодательного собрания штата, проголосовавшего за лишение чернокожих граждан права занимать выборные должности [Johnson, 2017]. Тернер лишился своего поста. 3 сентября он выступил с гневной речью в законодательном собрании штата, заявив, что «не намерен пресмыкаться перед политиками», и назвав данное решение «беспрецедентно несправедливым». Именно в этой речи можно видеть отход от интеграционистских принципов, артикулируемых им ранее, и резкий поворот к «черному национализму». «Англосаксонская раса, сэр, весьма удивительна. Ни один человек не был ей так обманут, как я, за последние три недели. Я не знал, что в характере этой расы столько трусости и малодушия. Вероломство, проявленное джентльменами, принадлежащими к этой расе, поколебало мое доверие к нему больше, чем все, что я наблюдал со дня моего рождения», - говорил Тернер [Turner, 1868]. Эти заявления разительным образом контрастировали с тем, что он озвучивал ранее.

В 1869 г. Тернер был назначен республиканской администрацией почтмейстером Мейкона, штат Джорджия, но проработал в этой должности меньше года. Обвиненный в связях с проституткой и других нарушениях, при давлении администрации Улисса Гранта Тернер был отстранен от исполнения обязанностей. После он несколько лет проработал таможенным инспектором в Саванне, штат Джорджия. В это время идейно-политические воззрения Тернера претерпевают существенную трансформацию, становясь все более радикальными.

В 1870-е гг. на первый план выходит идея репатриации - возвращения афроамериканцев на историческую родину. При этом Тернер приветствовал принятие 15-й поправки 1870 г. [Turner, 1870] и Закона о гражданских правах 1875 г. [Turner, 1874], но категорически не принял решения Верховного суда США 1883 г., отменившего ряд его ключевых положений. К тому моменту Тернер уже всецело сосредоточился на общественной работе как проповедник и журналист. Фактически это ознаменовало окончательный поворот в сторону черного национализма и отдаление от республиканской партии, которую он называл «мертвой» [Turner, 1874]. Еще в 1876 г. Тернер был избран вице-президентом Американского колонизационного общества и генеральным директором книжного концерна AME, расположенного в Филадельфии, штат Пенсильвания. Последним в 1879 г. публикуется его работа «Эмиграция цветного населения из Соединенных штатов» [Turner, 1879], в которой Тернер, как некогда другой именитый «отец черного национализма» Мартин Делани, подробно обосновывал необходимость переселения негритянского населения США на Черный континент [Шумаков, 2020, с. 60-61].

В 1880 г. он был избран первым епископом AME в Южных штатах. О полном его разочаровании в республиканской партии свидетельствует то, что на президентских выборах того же года Тернер не поддержал ни одного из кандидатов и охарактеризовал свое состояние как «близкое к мятежу» [Turner, 1880].

На протяжении последующих лет Тернер последовательно работал над реализацией своего эмиграционного проекта, совершив в 1890-х гг. четыре поездки в Либерию и Сьерра-Леоне. С этой целью им было создано Общество международной эмиграции, которым в 1895 и 1896 гг. были осуществлены две экспедиции в Либерию. Однако Тернера, как и Пола Каффи и Мартина Делани, ждало жестокое разочарование. Желающих отправиться на родину предков оказалось не так много - чуть более 500 чел., некоторые из которых впоследствии вернулись в США. Тем не менее это не заставило Тернера отказаться от своего проекта. Он по-прежнему считал африканскую эмиграцию «единственным лекарством от нарушенного положения вещей в этой стране» [Turner, 1899], а массовую эмиграцию ненужной и даже вредной на данном этапе.

В ответ на критику афроамериканский проповедник обвинял соотечественников в нежелании выносить неизбежные тяготы путешествий и колонизации. Он приводил в 
пример тяготы, выпавшие на долю отцов-пилигримов [Turner, 1897]. «Белая раса сделала это, - писал Тернер, - и негры должны сделать то же самое, или же они станут «притчей во языцех» на все грядущие времена. Негр должен продемонстрировать свою способность к выживанию среди сталкивающихся элементов расового насилия, двигаясь куда-то сам и хватаясь за естественные препятствия на пути просвещенной цивилизации и отбрасывая их в сторону. Ибо до тех пор, пока негр не уйдет куда-нибудь и не истребит диких зверей, не сравняет леса, не наведет мосты через реки, не засадит поля, не построит дома, не построит железные дороги и телеграфные линии, не построит свои школы и колледжи, не издаст свои законы, не утвердит правительство и не бросит вызов уважению человечества, он никогда не завоюет уважения всего мира. (...) Ибо если негр не может этого сделать, ему незачем надеяться наслаждаться благами человеческой расы, ибо он неудачник, если же он может, но не хочет, то просто не заслуживает того, чтобы наслаждаться ими» [Turner, Turner Scores His Critics, 1897, p. 4].

Лозунг «Африка для африканцев», сформулированный ранее Мартином Делани и Эдвардом Блайденом, в трактовке Тернера приобретал провиденциалистское обоснование. «Бог в своей бесконечной доброте и мудрости создал Африку для негров, а негров - для Африки. Я верю в это так же сильно, как и в то, что светит солнце» [Thorne, 1899], - говорил Тернер. При этом в отличие от своих предшественников Тернер считал, что негроидная раса не имеет никакого будущего на американском континенте, где она увядает, деградирует и вымирает [Negro Race Dying, 1898], и что белый человек вполне может украсть Африку у черного.

В начале XX в. влияние вашингтонского епископа стало заметно ослабевать. Какое-то время Тернер продолжал заниматься журналистской работой, редактируя газеты «Voice of Missions» (1893-1900) и «Voice of the People» (1901-1904) [Johnson, 2012]. До 1908 г. он оставался председателем Совета директоров Колледжа Морриса Брауна в Атланте - первого в Джорджии учебного заведения, созданного чернокожими представителями АМЕ. В 1915 г. во время посещения Виндзора, провинция Онтарио, Канада, на Генеральной конференции AME Тернер скончался от обширного инсульта.

\section{Заключение}

Подводя итог, необходимо заметить, что становление и последующая эволюция идейно-политической философии Генри Тернера проходили в несколько этапов. Первый (1851-1862) связан с классическим аболиционизмом и постепенным нарастанием скептических настроений в отношении дальнейшей судьбы чернокожего населения на территории США. Второй (1862-1868) - с резким разворотом в сторону интеграционизма и ярко выраженным оптимизмом в отношении будущего черной расы в Новом Свете и позитивного изменения американской социально-политической системы. На этом этапе Тернер активно включается в политическую борьбу и становится убежденным республиканцем. Третий (1868-1875) - постепенный отход от интеграционизма, разочарование в республиканской партии, в политической системе США и поворот к черному национализму. Четвертый (1875-1915) - формирование доктрины черного национализма и панафриканизма, работа над эмиграционным проектом.

Эволюция идейно-политических воззрений Генри Тернера тесно связана с социально-политическими процессами, происходившими в США. Если аболиционистские взгляды в ранние годы были обусловлены детскими переживаниями, а нарастающий скепсис - с наступлением на права чернокожих (в частности принятием Закона о беглых рабах 1850 г., актом Канзас - Небраска 1854 г., вынесением решения по делу Дреда Скотта в 1857 г. и прочими документами), то с принятием «Прокламации об освобождении рабов» в сентябре 1862 г. Тернер приходит к прямо противоположным выводам. Как и многие лидеры афроамериканского движения, он принимает сторону Армии Союза, видя в войне шанс на долгожданное освобождение своего народа и достижение социально-расового 
равноправия в своей стране. Но по мере свертывания политики реконструкции Юга Тернер окончательно разочаровывается в республиканской партии. Данный поворот был связан с полным крушением надежд на достижение расового равноправия в США. Первым толчком, очевидно, стало принятие в 1868 г. постановления Законодательного собрания штата Джорджия о лишении чернокожих граждан права занимать выборные должности, коснувшееся лично Тернера, а также ряд других нормативно-правовых актов и очевидное нежелание выполнять прежние обещания со стороны правительства. Если до 1875 г. он занимал двойственную позицию, то после завершения реконструкции и наступления эпохи Джима Кроу взгляды епископа становятся радикально националистическими, епископ начинает работу над своим иммиграционным проектом, видя в нем единственный выход из сложившейся ситуации, констатируя невозможность достижения расового равноправия в США.

Возрождение интереса к персоне епископа Тернера связано с растущей популярностью идеологии черного национализма в американском обществе. Если до конца 1960-х гг. данное направление считалось откровенно маргинальным в Движении за права чернокожих, где преобладали интеграционистские настроения, то в 1970-х гг. по мере нарастания скептических настроений наблюдалась его постепенная реабилитация и пробуждение интереса непосредственно к истории афроамериканского народа или т. н. черной истории (Black History). И Генри Тернер как никто другой подходит на роль одного из главных символов борьбы. Его деятельность вдохновляла многих последователей, оказав огромное влияние на Движение за права чернокожих в США и отчасти предопределив вектор его политического развития. Это можно видеть по его идейным последователям, таким как Маркус Гарви и Малкольм Икс, использовавшим все те же риторические приемы и обоснования.

Обращение к персоне епископа Тернера и его идеям в период очередного обострения расовых противоречий, нарастания скептических настроений, деконструкции государственной идеологии и побуждения национального сознания выглядит вполне обоснованным и логичным. Новой истории требуются новые герои... или хорошо забытые. Этим и объясняется «внезапный» феномен популярности Генри МакНила Тернера.

\section{Список литературы}

1. Армейсков С.А. 2010. Конструирование черной культурной идентичности в первой трети XX века: Маркус Гарви: дисс. ... канд. культурологии. М., РГГУ, 172.

2. Шумаков А.А. 2020. Проблема появления «черного национализма» в США. Приднепровский научный вестник. Т. 3. 8: 53-64.

3. A Call to Action. Christian Recorder: October 4, 1862. Электронный pecypc. URL: http://www.thehenrymenealturnerproject.org/2017/05/a-call-to-action.html (дата обращения: 12 декабря 2020).

4. Angell S.W. 1988. Henry McNeal Turner and Black Religion in the South, 1865-1900: diss. ... Doctor of Philosophy in Religion. Nashville, Tennessee. Vanderbilt University, 657.

5. Foster T. 1976. The Black Nationalism of Bishop Henry McNeal Turner (1860-1900). Master of Arts in History. N.Y., Queens College, The City University of New York. MA Thesis, 98.

7. Johnson A.E. 2017. Henry McNeal Turner: Church Planter, Politician, and Public Theologian. Электронный pecypc. URL: https://www.patheos.com/blogs/rhetoricraceandreligion/2017/10/henrymcneal-turner-public-theologian.html (дата обращения: 12 декабря 2020).

8. Johnson A.E. 2012. The Enigma That Was Bishop Henry McNeal Turner. Электронный pecypc. URL: https://www.huffpost.com/entry/henry-moneal-turner_b_1948098 (дата обращения: 12 декабря 2020).

9. Johnson A.E. 2008. The Prophetic Oratory of Henry McNeal Turner. Diss. University of Memphis, 156.

10. Little L.S. 1993. A quest for self-determination: The African Methodist Episcopal Church during the age of imperialism, 1884-1916. PhD diss. Columbus. The Ohio State University, 257. 
11. Martin E.T. 1975. The Life of Henry McNeal Turner, 1834 to 1870 . Master of Arts. Tallahassee. College of Arts and Sciences, Florida State University. MA Thesis, 106.

12. Negro Race Dying Out Here New York Sun: October 10, 1898. Электронный ресурc. URL: http://www.thehenrymcnealturnerproject.org/2018/03/negro-race-dying-out-here-october-10.html (дата обращения: 12 декабря 2020).

13. Ponton M.M. 1917. Life and times of Henry M. Turner: the antecedent and preliminaryhistory of the life and times of Bishop H.M. Turner: his boyhood, education and public career, and his relation to his associates, colleaguesand contemporaries / by M.M. Ponton. Ponton M.M. (Mungo Melanchthon). Atlanta, Ga, A.B. Caldwell pub. co, 180.

14. Thorne W.H. From «Must the Negro Go?», by William Henry Thorne in A New Review of World-Literature, Society Religion Art and Politics. Decker Building, New York, 1899. Электронный pecypc. URL: http://www.thehenrymcnealturnerproject.org/2018/03/from-must-negro-go-by-williamhenry.html (дата обращения: 12 декабря 2020).

14. Treadwell A.M. 2017. A Third Wave Black Church Revolution: How the AME Church Evolved from 1841 to 1877, Narrated by the Life Experiences of Daniel Alexander Payne and Henry McNeal Turner. Diss. ... Doctor of Philosophy. Washington, D.C. Howard University, 173.

15. Turner H.M. 1870. A Speech on the Ratification of the Fifteenth Amendment. The Henry McNeal Turner Project. 1870, April 19. Электронный pecypc. URL: http://www.thehenrymcnealturnerproject.org/2019/04/a-speech-on-ratification-of-fifteenth.html (дата обращения: 12 декабря 2020).

16. Turner H.M. 1897. Bishop Turner Would Be Moses of his Race. Atlanta Constitution: Aug 1, 1897; pg. 21. Электронный ресурс. URL: http://www.thehenrymcnealturnerproject.org/2018/03/bishopturner-would-be-moses-of-his.html (дата обращения: 12 декабря 2020).

17. Turner H.M. 1866. Celebration of the First Anniversary of Freedom. The Henry McNeal Turner Project. January 1, 1866. Электронный pecypc. URL: http://www.thehenrymcnealturnerproject.org/2019/03/synopsis-on-january-1st-1866-henry.html (дата обращения: 12 декабря 2020).

18. Turner H.M. 1874. Civil Rights Bill. Christian Recorder: April 30, 1874. Электронный pecypc. URL: http://www.thehenrymcnealturnerproject.org/2017/10/civil-rights-bill-april-30-1874.html (дата обращения: 12 декабря 2020).

19. Turner H.M. 1879. Emigration of the Colored People of the United States. Is it expendient? If so where to? Philadelphia, Pa, Publication Department A.M.E. Church. Электронная книга. URL: https://www.dropbox.com/s/ap6nzx4in6qpamm/Emigration \%20of \%20the \%20Colored \%20People.pdf? $\mathrm{dl}=0$ (дата обращения: 12 декабря 2020).

20. Turner H.M. 1899. Negro Emigration to Africa. From The Independent Vol. LI, JanuaryDecember $1899 . \quad$ Электронный pecypc. URL: http://www.thehenrymcnealturnerproject.org/2018/03/negro-emigration-to-africa-from.html (дата обращения: 12 декабря 2020).

21. Turner H.M. 1897. Turner Scores His Critics. Atlanta Constitution: September 11, 1897; pg. 4. Электронный ресурс. URL: http://www.thehenrymcnealturnerproject.org/2018/03/turner-scoreshis-critics-atlanta.html (дата обращения: 12 декабря 2020).

22. Turner H.M. 1880. The Presidential Election of 1880. Christian Recorder: March 25, 1880. Электронный ресурс. URL: http://www.thehenrymcnealturnerproject.org/2017/10/the-presidentialelection-of-1880.html (дата обращения: 12 декабря 2020).

23. Turner H.M. 1862. Turner on the President's Message. Christian Recorder: March 21, 1862. Электронный ресурс. URL: http://www.thehenrymcnealturnerproject.org/2017/04/turner-on-presidentsmessage.html (дата обращения: 12 декабря 2020).

24. Turner H.M. 1868. Speech on the Eligibility of Colored Members to Seats in the Georgia Legislature. The Henry McNeal Turner Project. September 3, 1868. Электронный pecypc. URL: http://www.thehenrymcnealturnerproject.org/2019/03/speech-on-eligibility-of-colored.html (дата обращения: 12 декабря 2020). 


\section{References}

1. Armejskov S.A. 2010. Konstruirovanie chernoj kul'turnoj identichnosti v pervoj treti XX veka: Markus Garvi [The Construction of Black Cultural Identity in the First Third of the 20th Century: Marcus Garvey]: diss. ... kand. kul'turologii. M., RGGU, 172.

2. Shumakov A.A. 2020. Problema pojavlenija «chernogo nacionalizma»v SShA [The problem of the emergence of «black nationalism» in the United States.]. Pridneprovskij nauchnyj vestnik [Pridneprovsky scientific bulletin]. T. 3. 8: 53-64.

3. A Call to Action. Christian Recorder: October 4, 1862. Электронный ресурс. URL: http://www.thehenrymcnealturnerproject.org/2017/05/a-call-to-action.html (дата обращения: 12 декабря 2020).

4. Angell S.W. 1988. Henry McNeal Turner and Black Religion in the South, 1865-1900: diss. ... Doctor of Philosophy in Religion. Nashville, Tennessee. Vanderbilt University, 657.

5. Foster T. 1976. The Black Nationalism of Bishop Henry McNeal Turner (1860-1900). Master of Arts in History. N.Y., Queens College, The City University of New York. MA Thesis, 98.

7. Johnson A.E. 2017. Henry McNeal Turner: Church Planter, Politician, and Public Theologian. Электронный pecypc. URL: https://www.patheos.com/blogs/rhetoricraceandreligion/2017/10/henrymcneal-turner-public-theologian.html (дата обращения: 12 декабря 2020).

8. Johnson A.E. 2012. The Enigma That Was Bishop Henry McNeal Turner. Электронный pecypc. URL: https://www.huffpost.com/entry/henry-moneal-turner_b_1948098 (дата обращения: 12 декабря 2020).

9. Johnson A.E. 2008. The Prophetic Oratory of Henry McNeal Turner. Diss. University of Memphis, 156.

10. Little L.S. 1993. A quest for self-determination: The African Methodist Episcopal Church during the age of imperialism, 1884-1916. PhD diss. Columbus. The Ohio State University, 257.

11. Martin E.T. 1975. The Life of Henry McNeal Turner, 1834 to 1870. Master of Arts. Tallahassee. College of Arts and Sciences, Florida State University. MA Thesis, 106.

12. Negro Race Dying Out Here New York Sun: October 10, 1898. Электронный ресурс. URL: http://www.thehenrymcnealturnerproject.org/2018/03/negro-race-dying-out-here-october-10.html (дата обращения: 12 декабря 2020).

13. Ponton M.M. 1917. Life and times of Henry M. Turner: the antecedent and preliminaryhistory of the life and times of Bishop H.M. Turner: his boyhood, education and public career, and his relation to his associates, colleaguesand contemporaries / by M.M. Ponton. Ponton M.M. (Mungo Melanchthon). Atlanta, Ga, A.B. Caldwell pub. co, 180.

14. Thorne W.H. From «Must the Negro Go?», by William Henry Thorne in A New Review of World-Literature, Society Religion Art and Politics. Decker Building, New York, 1899. Электронный pecypc. URL: http://www.thehenrymcnealturnerproject.org/2018/03/from-must-negro-go-by-williamhenry.html (дата обращения: 12 декабря 2020).

14. Treadwell A.M. 2017. A Third Wave Black Church Revolution: How the AME Church Evolved from 1841 to 1877 , Narrated by the Life Experiences of Daniel Alexander Payne and Henry McNeal Turner. Diss. ... Doctor of Philosophy. Washington, D.C. Howard University, 173.

15. Turner H.M. 1870. A Speech on the Ratification of the Fifteenth Amendment. The Henry McNeal Turner Project. 1870, April 19. Электронный pecypc. URL: http://www.thehenrymcnealturnerproject.org/2019/04/a-speech-on-ratification-of-fifteenth.html (дата обращения: 12 декабря 2020).

16. Turner H.M. 1897. Bishop Turner Would Be Moses of his Race. Atlanta Constitution: Aug 1, 1897; pg. 21. Электронный ресурс. URL: http://www.thehenrymcnealturnerproject.org/2018/03/bishopturner-would-be-moses-of-his.html (дата обращения: 12 декабря 2020).

17. Turner H.M. 1866. Celebration of the First Anniversary of Freedom. The Henry McNeal Turner Project. January 1, 1866. Электронный pecypc. URL: http://www.thehenrymcnealturnerproject.org/2019/03/synopsis-on-january-1st-1866-henry.html （дата обращения: 12 декабря 2020).

18. Turner H.M. 1874. Civil Rights Bill. Christian Recorder: April 30, 1874. Электронный pecypc. URL: http://www.thehenrymcnealturnerproject.org/2017/10/civil-rights-bill-april-30-1874.html (дата обращения: 12 декабря 2020).

19. Turner H.M. 1879. Emigration of the Colored People of the United States. Is it expendient? If so where to? Philadelphia, Pa, Publication Department A.M.E. Church. Электронная книга. URL: 
https://www.dropbox.com/s/ap6nzx4in6qpamm/Emigration \%20of \%20the \%20Colored \%20People.pdf? $\mathrm{dl}=0$ (дата обращения: 12 декабря 2020).

20. Turner H.M. 1899. Negro Emigration to Africa. From The Independent Vol. LI, JanuaryDecember 1899.

Электронный pecypc.

URL:

http://www.thehenrymcnealturnerproject.org/2018/03/negro-emigration-to-africa-from.html (дата обращения: 12 декабря 2020).

21. Turner H.M. 1897. Turner Scores His Critics. Atlanta Constitution: September 11, 1897; pg. 4. Электронный ресурс. URL: http://www.thehenrymcnealturnerproject.org/2018/03/turner-scoreshis-critics-atlanta.html (дата обращения: 12 декабря 2020).

22. Turner H.M. 1880. The Presidential Election of 1880. Christian Recorder: March 25, 1880. Электронный pecypc. URL: http://www.thehenrymcnealturnerproject.org/2017/10/the-presidentialelection-of-1880.html (дата обращения: 12 декабря 2020).

23. Turner H.M. 1862. Turner on the President's Message. Christian Recorder: March 21, 1862. Электронный ресурс. URL: http://www.thehenrymcnealturnerproject.org/2017/04/turner-on-presidentsmessage.html (дата обращения: 12 декабря 2020).

24. Turner H.M. 1868. Speech on the Eligibility of Colored Members to Seats in the Georgia Legislature. The Henry McNeal Turner Project. September 3, 1868. Электронный ресурс. URL: http://www.thehenrymcnealturnerproject.org/2019/03/speech-on-eligibility-of-colored.html (дата обращения: 12 декабря 2020).

\section{ИНФОРМАЦИЯ ОБ АВТОРЕ}

Шумаков Андрей Андреевич, кандидат исторических наук, доцент кафедры гуманитарных дисциплин Тульского филиала Российского экономического университета им. Г.В. Плеханова, г. Тула, Россия

\section{INFORMATION ABOUT THE AUTHOR}

Andrey A. Shumakov, candidate of Historical Sciences, Associate Professor of the Department of Humanities, Tula Branch of the Russian University of Economics. G.V. Plekhanov, Tula, Russia 